\title{
ROCK2 Inhibitor KD025
}

National Cancer Institute

\section{Source}

National Cancer Institute. ROCK2 Inhibitor KD025. NCI Thesaurus. Code C128786.

An orally administered inhibitor of Rho-associated coiled-coil kinase 2 (ROCK2; ROCK-II), with potential immunomodulating activity. Upon administration, ROCK2 inhibitor KD025 binds to and inhibits the serine/threonine kinase activity of ROCK2. This inhibits ROCK2mediated signal transduction pathways and modulates various pro- and antiinflammatory immune cell responses. ROCK2 is upregulated in various diseases, including various fibrotic, neurodegenerative and autoimmune diseases. 